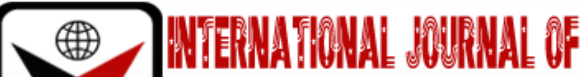

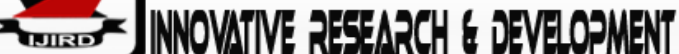

ISSN 2278-0211 (Online)

\section{Bio-mimicry: An Approach towards Sustainability in Resort Buildings}

\author{
Nwako Burabari Akpe \\ M.Sc. Student, Department of Architecture, Rivers State University, \\ Port Harcourt, Rivers State, Nigeria \\ Dr. Ferdinand F. O. Daminabo \\ Senior Lecturer, Department of Architecture, Rivers State University, \\ Port Harcourt, Rivers State, Nigeria
}

\begin{abstract}
:
Buildings consume a sizable proportion of any nation's power supplies. However, Resort schemes require large footprint of construction materials, consume more energy and emit greenhouse gases with the consequence of high environmental impact thus raising the issue of sustainability. Due to the increase in popularity of resort projects, achieving a high level of sustainability has become the focus in the architectural designs. There is now the need for combining technology and biology. Bio-mimicry is the art of imitating the best of nature to achieve designs that are pleasing to the eye, with high-energy efficiency and parameters that mitigates the adverse impact to the natural environment while creating a unique, aesthetically pleasing and a sustainable travel destination of good quality. This paper therefore adopts the analytical research approach of different studies and levels of bio-mimicry and how they are applied in resort buildings to achieve sustainability. Understanding and implementing bio-mimicry will add value and anticipated result to this laudable endeavor.
\end{abstract}

Keywords:Bio-mimicry, sustainability, resort building, energy efficiency

\section{Introduction}

In Nigeria, hotel and resort developments are just placed on beaches without exploiting the prospects and excitements that the beach offers as well as the beautiful embrace of nature. However, there is the need for a philosophical basis for individuals and organizations to literarily seek to redefine how buildings are designed, built and operated to be more responsive to the environment, people and to maximize the quality of the built environment. This will eliminate the negative impact on the natural environment and create an environmental ecosystem that is sustainable and ecofriendly. (Turner, and Soar (2008),

The relationship and connection between architecture and nature is one that has brought forth many questions, many criticisms, and many solutions and still many of these Solutions have not influenced society enough to make them universal. Buildings are created to shelter, to protect one from the elements. Kieran states, "The separation of man from nature is the motivation for the existence of architecture in the first place." Now, it almost seems unethical, to use architecture to separate man from nature. Solving the urban challenges those are different from the leading sustainability pattern are known as Bio-mimicry (Bonser \& Vincent, 2007).

Bio-mimicry (from the Greek words bios-life, and mimesis-mimic, imitate) is a design discipline that uses patterns and strategies of nature in the field of architecture and engineering, and is one of the tools to increase the sustainability of products, Materials and the built environment.

Bio-mimicry in architecture finds inspiration in the strategies, technologies and concepts that living organisms use to meet their needs and ensure their survival on earth. Self-regenerating and ecological architecture aim to resolve the tasks of designing, optimizing processes for that we find a parallel in nature, using minimal energy and materials. Considering that constructed buildings have a major impact on the environment, sustainable design strategies such as biomimicry, is becoming a more accepted method of achieving sustainable development and reducing the negative impact of humans on the environment that meets the needs of the present generations without compromising the ability of future generations to meet theirs. Application of the principles of bio-mimicry in architectural design and planning creates "living" objects that have the following performances: In fact, the principle of bio-mimicry is threefold; to use nature as a model, standard measure, and as mentor. This is explained to a greater depth in the subsections. This research therefore gives an insight to what bio-mimicry is all about and the different practical approaches that has been adopted; the principles that guides the adoption, the ways and how it mitigates the harsh technological effect to the environment and how nature can be infused into the modern trend of building without or with less negative effects.Todd (2003) 


\section{Approach of Bio-mimicry}

Bio-mimicry can rightly be effective when studied through different approaches. Therefore, the different levels that exist in the analysis of the subject matter can be highlighted through the levels below.

\subsection{Level 1:Natural form-Inspired Design}

The careful sighting of the elements and forms of nature and using it as a model greatly influence the actualization of Bio-mimicry. This is because nature has the high tendency to inspire the minds of architects and in-turn gives a great output in mimicking nature. The objective of form-inspired design is to mimic or copy the appearance or feature of the natural environment in the physical design. Below is an example of level

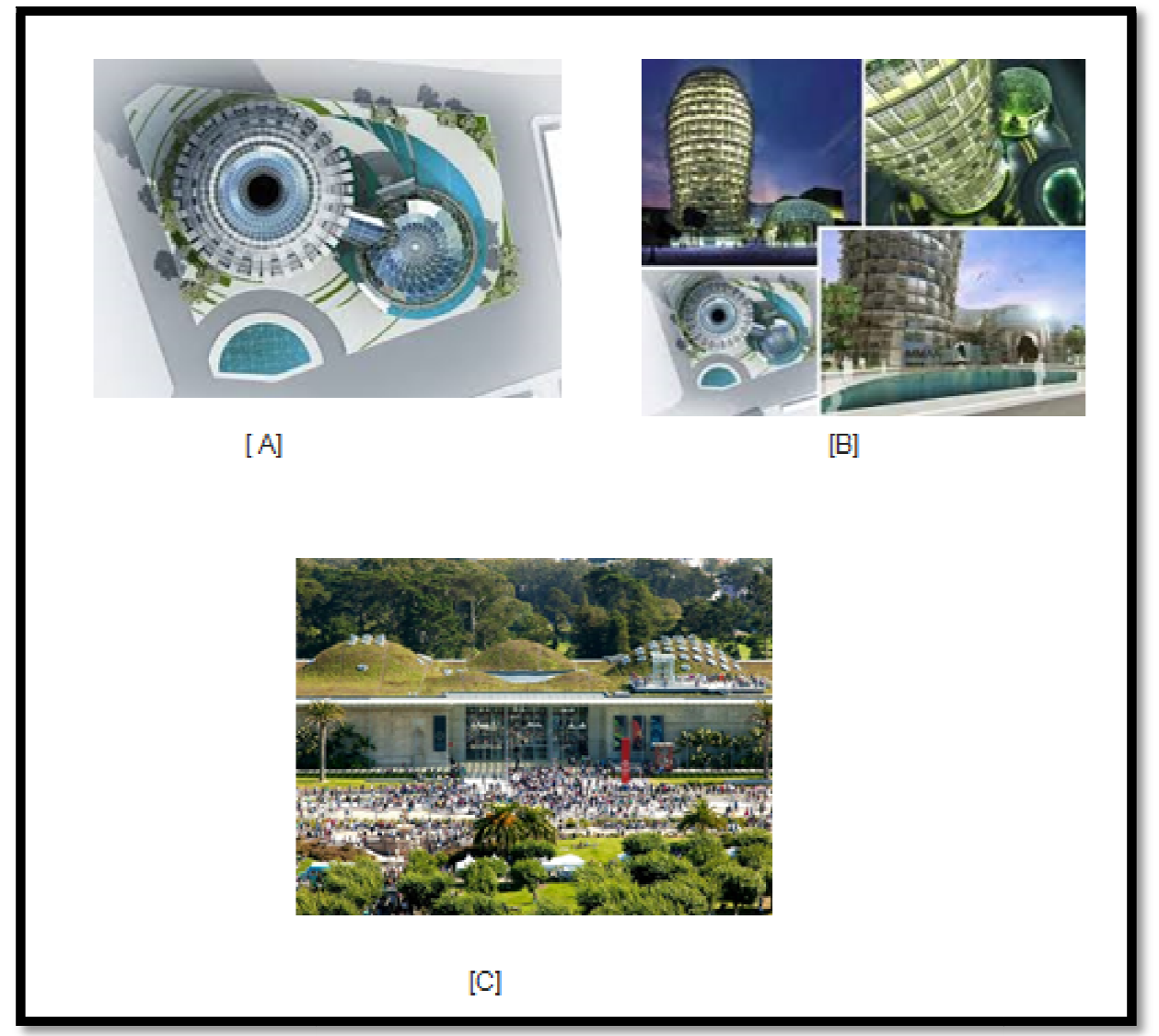

Figure 1: Showing Qatar Sprouts a Towering Cactus Skyscraper Source: Google Image Www. Https://Inhabitat.Com/Qatar-CactusOffice-Building/

The Modern Office and Adjoining Botanical Dome Take Cues from Cacti and the

Way That They Successfully Survive in Hot, Dry Environments.

\subsection{Level 2:Natural-Ecosystem-Inspired Design}

This level takes into consideration how designers try to study and incorporates the nature's interaction and relationship between the habitants and the environment. 


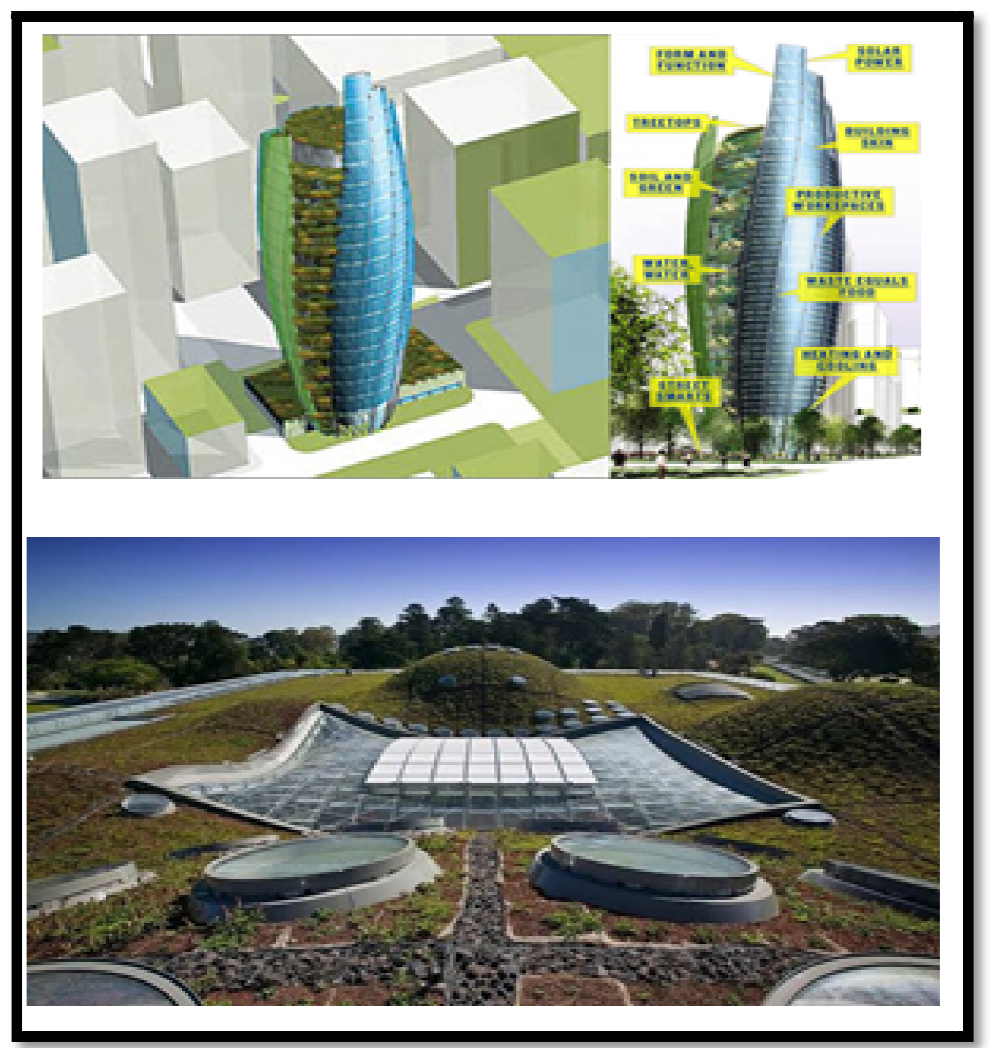

Figure 2: Showing California Academy of Sciences Museum Green Roof Source: Www.Greenroofs.Com

This level analyses the flow as well as merging of the natural environment within the built environment. Critical understanding of this level enables the designer not to have a conflicting or isolation design, instead the design flows and derives its existence from ecosystem. It mimics the pattern which nature emits and unifies it with nature existence.

This level not only emulates the appearance of natural dwelling places when designing a building but also tries to imitate and apply the activities that take place in the natural world. This includes the nature's interaction and relationship between the habitants and the environment.

\subsection{Level 3: Natural Processes-Inspired Design}

In the third level/type of bio-mimicry, the designers incorporate natural/biological processes in the design of the built environment. The design of the built environment is conceptualized to be similar to the processes that take place in the natural world.

Pearce Eastgate Project inspired from termite mounds that have the ability to produce natural heating and cooling

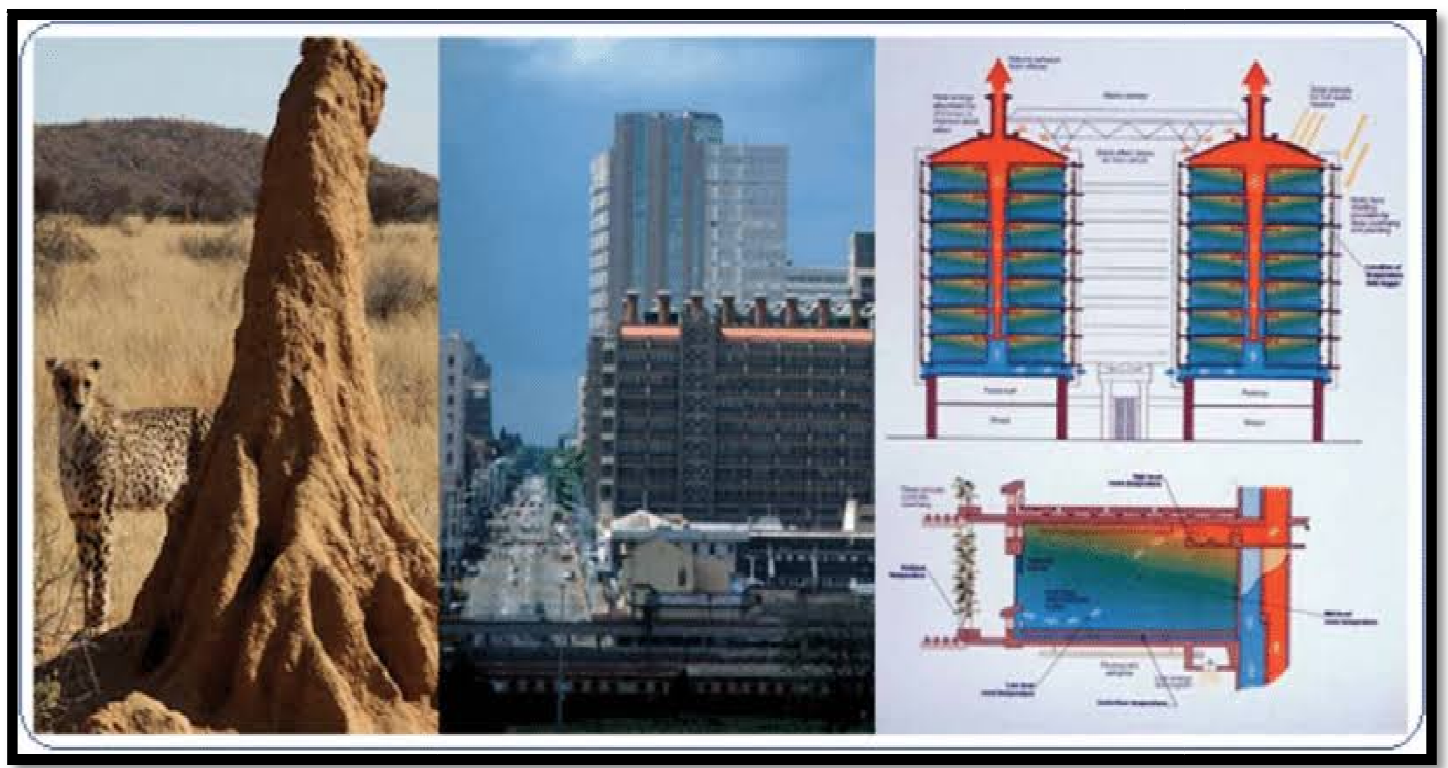

Figure 3: Showing the Pearce Eastgate Project Inspired from Termite Mounds That Have the Ability to Produce Natural Heating and Cooling 


\section{The Basic Principles of Bio-mimicry}

The level explained above can be studied through adhering to the rule of Bio-mimicry which are called principles of Bio-mimicry

Three (3) levels are highlighted by several scholars in the field and study of this subject matter. The application of bio-mimicry in the design of buildings significantly benefits the architects and sustainable designers. By integrating the principles emulated and inherited from the natural world, they can create a physical built environment that is selfsustaining. The design can incorporate sustainable systems for energy use, water consumptions and recycling of resources.

\subsection{Principle 1: Use of Nature as a Model}

The architects and building designers using these principles takes ideas through studying and investigating the levels of nature such as the form, the ecosystem and the processes, discussed earlier in the paper.The purpose is to create replicas of their natural models and most importantly to create self-sustaining buildings (Reed 2004).

Here the variables used are extracted from the principles of natural form of architecture.

Architects and designers aim at replicating buildings to assume a natural shape and form or they make buildings to depict symbol and geometric shapes that naturally emphasizes the intent. In this principles also building are planned such that it has a relationship with the environment in which the structure is to exist. The material types and the technological model adopted are also nature friendly.

\subsection{Principle 2: Exploring the Application of Natural Processes}

This principle's ultimate objective is to create a built environment that is closely similar to the natural environment; a built environment that can sustain and balance its available resources in order to address human caused problems such as pollution, global warming, and energy and water shortage.

This principle supports the use of standard, sustainable and non-degradable variablessuch as; the use of energy sources that do not degrade the environment from the point of generation up to the point of consumption by the final consumer and are renewable over time thus not posing a risk to future generations in terms of exhaustion or ecological degradation (Pam Baldinger, 2006).

\subsubsection{Variables}

Energy/power sources: This entails the use of renewable energy sources such as; use of high performance integrated photovoltaic façade systems

- $\quad$ Rain screens and stick systems

- Shading and Glazing systems

- Courtyards

- Use of photovoltaic panels for power generation.

- Employment of solar water heating.

This principle also involves the Energy management methods; this entails the proper management of available power through the selection of appliances with energy star ratings and also the exploitation of passive climatic design.

\subsection{Principle 3: Learning from the Ecosystem}

Nature as Mentor methods like day lighting and cooling of building interiors. Therefore, from studies, the methods that can be used include:

- Use of high-performance low e-glazing to minimize energy consumption.

- Use of sensors, controls and design circuits can be incorporated so that lighting fittings independently when day lighting is sufficient.

- Use of solar water heating.

\subsection{Principle 4: Learning from the Ecosystem (Nature as Mentor)}

This principle stipulates the preservation of the existing natural water cycle and site design and building improvements such that they closely emulate the site's natural "pre-development" hydrological systems.The emphasis is on retention of storm water and on-site filtration and ground water recharge using methods that closely emulate natural systems as well minimization of unnecessary and inefficient use of portable water on the site while maximizing the recycling and re-use of water, including harvested rainwater, storm water and grey water (governor's green government council, 2007).

\subsection{Significance of Bio-mimicry in Architecture}

Design Value: A Source of Inspiration

A single designer can be benefitted from the nature by the following ways:

\subsubsection{Nourish Curiosity}

Due to curious nature, the designers get some amount of opportunity to learn about water, energy and materialuse strategies. 


\subsubsection{Gobeyond form}

Taking reference from the history for the design cues has become a standard practice.

\subsubsection{Give Permission to Play}

Work environment can hardly be a creative environment. Out-going people have been shown happier and creative compared to those who are not so happy. These types of studies directly provide evidence that outdoor experiences boost the creativity.

\subsubsection{Project Value: It Gives a Framework for Innovation} framework.

The designer team can bring new perspectives to their projects by using the Bio-mimicry DesignLens as a

\subsection{Disrupt Traditional Thinking}

Trying to find solution from the nature helps the project teams to explore the new solutions and opportunities in a new and innovative ways.

\subsection{Accomplish Multiple Objectives with a Single Gesture}

Generally, a tool of the nature can't be a single purpose tool. For example, trees generate energy, and bark, which also help to protect and cool the moving water beneath the surface.

\subsection{Adaptto Context and Climate}

Projects with cyclic processes help to fight against the climate (Baumeister, 2013).

\subsection{Leverage Collaboration}

Cultivative and collaborative projects help to save and nurture resources, energy and cost for the project as well as the community.

\subsection{Embody Resilience}

Incorporation of diversity and personifying resilience through variation helps to create human-built systems that are inherently resilient to disturbances.

\section{Conclusions}

Emulating the nature's growth and ambience in the design of structures especially a resort leaves the user with a smoothening comfort that comes with relaxation as nature does not stress in evolution. Therefore, considering mimicking nature which is Bio-mimicry is never an objectionable option when it has to do with designing for Habitation.

This is because every habitation must enhance life and nature as the latter is an embodiment of life. To this end, this subject matter cannot be over emphasized but emboldened as essential and acceptable parameter towards a sustainable built environment.

\section{References}

i. Batty, M, (2013), "The future cities agenda" Environment and Planning B: Planning and Design 40(2) 191-194.

ii. Batty, M, Axhausen, K W, Giannotti, F, Pozdnoukhov, A, Bazzani, A, Wachowicz, M, Ouzounis, G, and Portugali, Y, (2012), "Smart cities of the future" The European Physical Journal Special Topics 214(1) 481-518.

iii. Baumeister, D, (2013) Biomimicry Resource Handbook: A Seed Bank of Best Practices (Biomimicry 3.8, Missoula, Montana).

iv. Benyus J. M., (2009): Biomimicry: Innovation Inspired by Nature, HarperCollins,.

v. Benniston, A C and Harriman, A, (2008), “Artificial photosynthesis" Materials Today 11(12) 26-34. Benyus, J, 1997 Biomimicry: innovation inspired by design (Harper Perennial, New York).

vi. Benyus, J M, (2008), "A good place to settle: Biomimicry, biophila, and the return to nature's inspiration to architecture", in Biophilic design: The theory, science, and practice of bringing buildings to life (Wiley, Hoboken, NJ). 39

vii. Biomimicry 3.8, 2015, “Biomimicry DesignLens", http://biomimicry.net/about/biomimicry/biomimicrydesignlens/.

viii. Biomimicry Oregon, (2013), "Nature's Strategies for Managing Stormwater in the Willamette Valley, Genius of Place Project Report", Oregon.

ix. Bonser, R H C and Vincent, J F V, (2007), "Technology trajectories, innovation, and the growth of biomimetics" Proceedings of the Institution of Mechanical Engineers, Part C: Journal of Mechanical Engineering Science 221(10) 1177-1180.

X. Boot-Handford, M E, Abanades, J C, Anthony, E J, Blunt, M J, Brandani, S, Mac Dowell, N, Fernández, J R, Ferrari, MC, Gross, R, Hallett, J P, Haszeldine, R S, Heptonstall, P, Lyngfelt, A, Makuch, Z, Mangano, E, Porter, R T J, Pourkashanian, M, Rochelle, G T, Shah, N, Yao, J G, et al, (2014), “Carbon capture and storage update" Energy \& Environmental Science 7(1) 130-189.

xi. Edwards, R, Ribbens, J, and Gillies, V, 1(999), "Shifting Boundaries and Power in the Research Process: the Example of ResearchingStep-Families"” Explorations in Sociology 57 Pages13-42. 
xii. Eryildiz S., Mezini L. (2012), Bio-architecture - Inspirations From Nature, Gazi University

xiii. Journal of Science, 25(1), 263-258,

xiv. Helms, M. E, Vattam, S. S, Goel, A K, Yen, J, and Weissburg, M, (2008), "Problem-Driven and Solution-Based Design: Twin Processes of Biologically Inspired Design", in Acadia08 Conference.

xv. Nakrani, S. and Tovey, C, (2004), "On Honey Bees and Dynamic Server Allocation in Internet Hosting Centers" Adaptive Behavior 12(3-4) 223-240.

xvi. Taylor Buck, N. (2015) The Art of Imitating Life: The Potential Contribution of Biomimicry in Shaping the Future of Our Cities. Environment and Planning B: Planning and Design. ISSN 0265-8135

xvii. Todd, J, (2003), "Omega Center for Sustainable Living Eco-Machine Case Study",

xviii. Turner, J S and Soar, R C, (2008), "Beyond biomimicry: What termites can tell us about realizing the living building", in First International Conference on 48 Industrialized, Intelligent Construction (I3CON) Loughborough University, pp 14-16. 